\title{
STUDY OF DENGUE INFECTION IN RURAL RAJASTHAN
}

\author{
Manisha Rathi' ${ }^{1}$, Rupesh Masand ${ }^{2}$, Alok Purohit ${ }^{3}$
}

\section{HOW TO CITE THIS ARTICLE:}

Manisha Rathi, Rupesh Masand, Alok Purohit. "Study of Dengue Infection in Rural Rajasthan". Journal of Evolution of Medical and Dental Sciences 2015; Vol. 4, Issue 39, May 14; Page: 6849-6859,

DOI: $10.14260 /$ jemds/2015/993

ABSTRACT: BACKGROUND: Dengue has a wide spectrum of clinical presentation in paediatric population, often with unpredictable evolution and outcome. AIMS: To record the clinical, laboratory \& radiological profile of dengue in hospitalized children and to enlist the predictive markers of severity in patients with severe dengue. SETTINGS AND DESIGN: This observational, prospective hospital- based study was conducted in 100 admitted children aged 9 months - 18 years with clinical and laboratory confirmation of dengue illness. METHODS: All the 100 subjects included in this study were classified in three groups- Dengue without warning signs (D) Dengue with warning signs (DW) and severe dengue (SD) on the basis of 2009 WHO Guidelines followed by laboratory and radiological evaluation. STATISTICAL ANALYSIS: involved summarizing the continuous variables as mean and standard deviation, while nominal/categorical variables were expressed as percentages. Chi square test was used for analysis of nominal/categorical variables. Stepwise Multivariate Logistict Regression analysis was employed to determine the predictors for severe dengue. RESULTS: 52 patients had dengue without warning signs (D), 40 patients had dengue with warning signs (DW) and 8 patients had severe dengue (SD). Fever was present in 52(100\%) cases, myalgia in $31(59.62 \%)$ cases followed by hepatomegaly in $20(38.46 \%)$ cases was seen in D group while in DW group fever in $40(100 \%)$, vomiting in $34(85 \%)$, pain abdomen in $33(82.50 \%)$ and hepatomegaly in $11(52.50 \%)$ cases was seen. In SD group, fever, myalgia, vomiting, pain abdomen, rash, positive Hess test, pallor, hepatomegaly was observed in all the cases (P value $<0.001$.). Presence of commonly described features like rash (13\%), positive Hess test (8\%) and bleeding manifestations (7\%) in few cases only was a prominent feature observed in the study subjects. Raised SGOT/ SGPT levels, prolonged PT and APTT, hypoalbuminemia, pleural effusion in skiagrams of chest and increased gall bladder wall thickness (GBWT)>3mm in USG scan was significantly associated with SD. Among several predictors, GBWT was observed to be strongly correlating with severity of dengue infection. CONCLUSION: Dengue is becoming more prevalent in India especially in rural areas. As it may have a non-specific presentation, it should be suspected in every case of febrile illness in post-monsoon season.

KEYWORDS: Dengue; rural; children.

INTRODUCTION: Dengue is an acute febrile disease caused by the mosquito-borne dengue virus (DENV) of the Flaviviridae family. ${ }^{1}$ The World Health Organization (WHO) approximates an annual incidence of 100 million infections out of which 500,000 people with dengue hemorrhagic fever (DHF) require hospitalization, with a large proportion being children. In the last 50 years, incidence has increased 30-fold with increasing geographic expansion to new countries and in the present decade, from urban to rural settings. ${ }^{1-4}$ The infection by either of four DENV serotypes- 1 to 4 may be asymptomatic or may present as undifferentiated acute febrile illness, classical dengue fever (DF) or as severe dengue- Dengue hemorrhagic fever (DHF) or Dengue shock syndrome (DSS) where the mortality rate is approximately $1-2.5 \% .{ }^{5}$ Owing to this variable clinical expression \& disease severity 


\section{ORIGINAL ARTICLE}

and due to the paucity of data regarding its occurrence in paediatric population of adjoining rural areas, this study was conducted to record the clinical, laboratory and the radiological profile of dengue illness in hospitalized children belonging from rural areas of Jaipur district in Rajasthan \& to enlist the predictive markers of severity in patients with severe dengue.

METHODS AND MATERIALS: This observational, prospective, hospital-based study was conducted in the Department of Paediatrics, NIMS Medical College and Hospital, Jaipur between January 2013 and December 2013 after obtaining clearance from Institutional Ethical Committee and informed consent from the parent/ guardian of study subjects. This tertiary care Centre is located $50 \mathrm{~km}$ from Jaipur City amidst rural surroundings. 100 children between the age group of 2 months to 18 yrs admitted in the Paediatric Ward or Paediatric intensive care unit with symptoms and signs suggestive of dengue illness and with serological confirmation (NS1, IgM and/or IgG positive for dengue with rapid diagnostic kit) were included in the study. Patients with NS1-negative or IgM and IgG-negative dengue- like illness, or bearing concomitant presence of other infections such as malaria, typhoid, hepatitis A and scrub typhus were excluded from this study. After taking a detailed history and performing a meticulous clinical examination, laboratory investigations were carried out which included hemoglobin, total and differential white blood cell (WBC) count, platelet count, hematocrit (Hct), peripheral blood smear, rapid diagnostic tests for Malaria parasite, typhoid and scrub typhus, IgM for Hepatitis A virus, prothrombin time (PT), partial thromboplastin time (PTT), liver function tests, renal function tests, radiological investigations like chest X-ray, ultrasonography (USG) of abdomen and chest and as warranted by the clinical condition of the study subjects.

Tourniquet test was performed by inflating the appropriately sized blood pressure (BP) cuff on the upper arm to a point midway between systolic BP and diastolic BP for 5 minutes. If the resulting petechiae in an area of $6.25 \mathrm{~cm} 2$ (i.e. $2.5 \times 2.5 \mathrm{~cm}$ ) was $\geq 20$, it was considered a positive test. Heart rate, BP, platelet count \& haematocrit were monitored daily for first five days after admission. The study subjects were classified and grouped on the basis of their clinical presentation, according to the new WHO/ TDR classification $2009^{6}$ as Dengue without warning sign (D), Dengue with warning signs (DW) and Severe Dengue (SD) following which treatment was commenced as per standard WHO 2011 Guidelines. ${ }^{7}$ The clinical, laboratory and radiological investigations of all the study subjects was recorded in a specially designed pretested proforma. Qualitative detection of NS1, IgM and IgG was performed by using rapid diagnostic test kit (Dengue Day1 Test ${ }^{\mathrm{TM}}$ manufactured by J. Mitra and Co. Pvt Ltd) on human serum or plasma sample.

Statistical analysis involved summarizing the continuous variables as mean and standard deviation, while nominal/categorical variables were expressed as percentages. Chi square test was used for analysis of nominal/categorical variables. Stepwise Multivariate Logistict Regression analysis was done to find out predictors for severe dengue. All the analysis as mentioned above was performed using Med Calc 14.0.0 version software. P value $<0.05$ was taken as significant.

ETHICS: The permission to carry out the study was granted by NIMS Ethics Committee.

RESULTS: A total of 100 patients were included in this study. 51(51\%) patients were $>12$ yrs of age followed by $23(23 \%)$ in age group of $8-12$ yrs (Table 1 ). The mean age was 11.60 years. The youngest in the series was 9 months and oldest was 18 yrs of age. M: F ratio was 2.6:1. 


\section{ORIGINAL ARTICLE}

$52(52 \%)$ cases were classified in group of Dengue without warning signs (D) followed by 40 $(40 \%)$ cases in group of Dengue with warning signs (DW) and 8(8\%) cases in severe dengue (SD) group. (Fig. 1)

During the study period from January till December 2013, majority of the study subjects were admitted in the months of August (17\%), September (43\%) and October (26\%), (Fig. 2). Fever was reported in $52(100 \%)$ cases followed by myalgia in $31(59.62 \%$ ) and hepatomegaly in $20(38.46 \%)$ cases in D group while in DW group, fever was observed in $40(100 \%)$ followed by vomiting in $34(85 \%)$, pain abdomen in 33(82.50\%) and hepatomegaly in $11(52.50 \%)$ cases. In SD group presence of fever, myalgia, vomiting, pain in abdomen, rash, positive Hess test, pallor, hepatomegaly was seen in all the cases (P value $<0.001$.). Presence of commonly described features like rash $(13 \%)$, positive Hess test (8\%) and bleeding manifestations (7\%) in only few cases was a prominent feature observed in the study subjects. (Table 2)

Laboratory, serological and radiological analysis have been summarized in Table 3, 4, 5 \& 6. In this study, leucopenia was seen in $43(43 \%)$ cases and particularly had no relation with severity of dengue illness $(\mathrm{P}=0.167)$. Thrombocytopenia was characteristically observed in $75(75 \%)$ cases. However, a normal platelet count was conspicuously recorded in the remaining (25\%) subjects. Bleeding manifestations were observed in 7 cases only. In 1 case of SD group, it was significantly absent even with a platelet count of $<20 \times 10^{9} / \mathrm{L}$. Raised SGOT and SGPT levels, prolonged PT and APTT, hypoalbuminemia, pleural effusion in skiagrams of chest and increased gall bladder wall thickness (GBWT) $>3 \mathrm{~mm}$ in USG scan was significantly $(\mathrm{p}<0.05)$ associated with SD. NS1 positivity was significantly helpful in early diagnosis of dengue illness as compared with patients presenting with SD where qualitative IgM and IgG estimation established the diagnosis. In the Stepwise Multivariate Logistict Regression analysis model, the features entered as independent factors were prolonged PT, APTT, hypoalbuminemia $(<2.5 \mathrm{~g} / \mathrm{dl})$, positive Hess test, Positive IgM and increased GBWT $>3 \mathrm{~mm}$. Only GBWT was retained in model as significant predictive marker for severe dengue (OR=66; 95\%CI 9.9892 to 436.0721). 94\% of cases were correctly classified by model (AUC of ROC curve $=0.853$ ).

DISCUSSION: This study was performed to document the clinical, laboratory and radiological profile of dengue fever in children belonging from rural areas of Jaipur district in Rajasthan. Though the study was carried out between January and December 2013, majority of cases were admitted during the monsoon and post monsoon period i.e. September and October which is similar to the observation by Kulkarni et al $^{8}$ and Rasul et al. ${ }^{9}$

Out of a total of 100 dengue sero-positive cases, 52(52\%) patients had D, 40(40\%) patients had DW and $8(8 \%)$ patients had SD. Though 52\% of study subjects presented without warning signs, they were still admitted in the Paediatric Ward owing to apprehension among parents in relation to the disease manifestations and occurrence of similar such cases in their neighbourhood.

In this study, age of the study subjects ranged from 9 month-18 years (mean $=11.6$ years). Shah et al ${ }^{10}$ observed a similar age range of 8 month - 14 years in their study. Other studies ${ }^{11-12}$ have observed a mean age of 8.3 years and 4.9 years respectively. Neonatal Dengue is very rare. None of the subjects were neonates in this study. However, there were two affected infants aged 9 months each. Kulkarni et al ${ }^{8}$ observed 6 neonates affected with dengue fever. This may be partly explained by the larger sample size $(n=948)$ considered in their study. 


\section{ORIGINAL ARTICLE}

In the present study, more than two-thirds of the study subjects were males. This observation may be explained by the fact that all our study subjects belonged from rural areas where gender bias is highly prevalent and was similar to that observed by Kulkarni et al. ${ }^{8} \mathrm{~A}$ higher proportion (60\%) of severe dengue in female children than in males was observed which is in consonance with Kabra et al. ${ }^{13}$ Fever was observed in all the study subjects with a mean ( \pm SD) duration of 5.42( \pm 3.69 ) days, which was similar to other studies.14-16 None of the patients had classic biphasic fever and 'breakbone' fever, as classically described in dengue and as similarly observed by Joshi et al. ${ }^{14}$ Altered sensorium with absence of seizures was present in four patients of SD group. This may be explained by the fact that dengue infection can cause neurologic manifestations secondary to cerebral hypoperfusion as in shock. However, encephalopathy as a complication was observed in one patient of severe dengue among the above. Unusual or atypical presentations like an upper respiratory tract infection, diarrhea, jaundice, exfoliative dermatitis were not observed, as recorded by Ratageri et al 15 in their study.

Out of 100 cases, bleeding manifestations were observed in 7 cases only in the form of petechiae $(n=2)$, epistaxis $(n=2)$, melena $(n=1)$ and haemetemesis $(n=1)$. This is in contrast to the observation by other authors11,14-16 who observed significant number of cases with bleeding manifestations.

Hess (Tourniquet) test was positive in only eight patients (8\%) of study subjects, in contrast to other studies8,10 where it was positive in a significantly higher percentage of patients. Low proportion of positive tourniquet test in our patients may be due to the darker skin color or due to the different strain of dengue virus affecting the Indian subcontinent. ${ }^{16}$ This test has a sensitivity of $41.6 \%$, specificity of $94.4 \%$, positive predictive value of $98.3 \%$, and negative predictive value of $17.3 \%$ for dengue infection. ${ }^{17}$

A possible reason for the significant differences seen in the clinical expression of the disease mentioned in different studies (Table 7) may be due to infection with different DENV serotypes and the possibility of concurrent infections with more than one serotype. Co-circulation of multiple DENV serotypes has been reported from many parts of the world, including India during an outbreak of DHF/DSS in 2006. There is, however, limited documentation describing concurrent infections with more than one serotype in the same individual.18,19 Furthermore, as already alluded to, sequential infection with more than one serotype is thought to be a major factor for the emergence of DHF. However, virulence is not the only factor to explain differences in host susceptibility to the disease and disease severity. Host immune response variations have been associated with polymorphism in the human genome, which may help explain why some patients develop end-stage complications in dengue disease and others only experience a mild form of the disease. In another study of children with DENV infection, host genetic differences were shown to affect the immune response and consequently, influence disease outcome.20,21

There was no significant statistical correlation between hematocrit and severity of disease among the clinical subgroups of dengue. The classical description of $>20 \%$ rise in the hematocrit is difficult to establish, as reference standards have not been established for Indian children. Hence the rise in hematocrit was not taken as a diagnostic criteria. Moreover, Indian children with SD have a lower than expected rise in hematocrit during the plasma leakage period. This has been attributed to the high prevalence of iron deficiency anemia in the general population. Thus, hematocrit may not be a good indicator of monitoring fluid therapy in infants and children in presence of moderate anemia 


\section{ORIGINAL ARTICLE}

in our study population. However, the criterion of $>20 \%$ fall in hematocrit level after sufficient treatment with intravenous fluid therapy may help in retrospective diagnosis of DW and SD groups. Further research is required in this direction to establish age related baseline hematocrit values in Indian children. There was no correlation between low platelets count (75\% cases) and bleeding manifestations $(n=7)$ in this study. However, bleeding was observed in cases with severe thrombocytopenia (statistically significant) associated with severe dengue in 6 out of 8 cases. This is in contrast to studies by Joshi et $\mathrm{al}^{14}(96 \%)$ and Dhooria et $\mathrm{al}^{22}$ who observed thrombocytopenia in all their study subjects.

The platelet counts on hospital admission were neither an indicator of prognosis nor of progression of the disease. 25 patients in this study had a normal platelet count on admission despite having serological evidence of dengue infection. However, studies which include only severe dengue cases show correlation between low platelet count and bleeding manifestations as observed by other authors. ${ }^{16,23}$ However, platelet count provides a very useful means of diagnosis at the screening level.

Both SGOT and SGPT were observed to be raised in $80 \%$ of study subjects. Elevation of SGOT was more compared with SGPT in the present study and was similar to other observations. It may be due to involvement of myocytes which has clinically manifested as myalgia. The present study did not demonstrate a significant difference in the LFT's between the clinical subgroups of dengue. Though, raised transaminase level may be deemed as non-specific marker of infection and stress but in combination with vomiting and hepatomegaly may serve as an indicator of dengue infection during an epidemic.

Ultrasound was found to be superior when compared with chest $\mathrm{x}$-ray to detect plasma leakage. The low sensitivity of radiograph is because of the fact that x-ray films are not ideal for detecting small amounts of effusion while ultrasound is highly helpful. An earlier study from Indonesia also reported such discrepancies in findings related to these investigations. Ultrasound is ideal owing to its safety and that it is non-ionizing and would assist in detecting plasma leakage even before it clinically manifests. Similar findings have been reported earlier from Indonesia. ${ }^{24}$

NS1 Ag circulates uniformly in all serotypes of dengue virus and it circulates at high level during the first few days of illness. ${ }^{25} \mathrm{NS} 1 \mathrm{Ag}$ levels varies from $0.04-2 \mu \mathrm{g} / \mathrm{ml}$ in acute-phase serum samples, to only $0.04 \mu \mathrm{g} / \mathrm{ml}$ or even less in convalescent phase serum. ${ }^{26}$ This is the reason for its higher detection rate in acute phase sera. In this study, patients with D (78\%) and DW (67.5\%) were diagnosed using NS1 antigen detection test kit. However patients with severe dengue were negative for NS1 antigen owing to fact that they had febrile illness of more than eight days duration.

The morbidity and the mortality of dengue illness can be reduced by early diagnosis, hospitalization and symptomatic care. In this study $68 \%$ study subjects were detected in the first four days of illness by NS1 Ag assay. Studies claim that in addition to an early diagnosis, NS1 antigen may be an indicator of disease severity. ${ }^{26}$ Libraty et al observed that a very high concentration of NS1 antigen within 72 hours of illness identified patients at risk of developing DHF. ${ }^{27}$ A quantitative estimation of NS1 Ag was however, not carried out in this study to confirm this observation.

Detection of specific IgM by MAC-ELISA is still used as the diagnostic technique for acute infection; its disadvantage being delayed appearance of antibodies from 5-10 days after the onset of illness in case of primary dengue virus infection and 4-5 days after the onset of illness in secondary infections. ${ }^{28}$ The requirement of paired sera, subsequently in convalescent phase, if negative in acute phase also delays diagnosis. Sensitivity and specificity of IgM and IgG detection by test kit is $100 \%$ 


\section{ORIGINAL ARTICLE}

and $99.98 \%$ respectively and for NS1, sensitivity and specificity is $100 \%$ and $99.94 \%$. Serological investigation for IgM detection in convalescent period could not be performed in this study owing to financial limitations.

In this study all 100 patients were given intravenous fluid and antipyretics. Platelet transfusion was given in 3 cases of severe dengue. It was observed that outcome of patients does not correlate with platelet transfusion and it was statistically significant ( $p$ value $<0.05$ ). Moreover, mortality was observed in those three cases despite platelet transfusion.

Out of 100 children, 97 cases recovered without any sequelae and were discharged subsequently. Mortality was observed in 3(3\%) cases due to acute respiratory distress syndrome $(n=2)$ and encephalopathy $(n=1)$. All three patients were admitted in PICU and required mechanical ventilation.

Gall bladder wall thickness (GBWT) $>3 \mathrm{~mm}$ in USG scan was observed as significant predictive marker for severe dengue (OR $=66$; $95 \%$ CI 9.9892 to 436.0721 ) in this study which was similar to the observation by other authors. $8,29,30$

The limitations of this study were that some cases exhibiting symptoms and signs suggestive of dengue illness were not included because they were sero-negative for dengue infection. Specific serotype detection facility for dengue virus was not available at institutional level. Further, advanced techniques like ELISA were unavailable, hence could not be employed to detect IgM and IgG for dengue infections.

To conclude, dengue illness may have a non-specific and varied presentation in pediatric population, thus mandating its screening in every case of febrile illness especially during the postmonsoon season of the year. NS1 antigen detection test facilitates early diagnosis and GBWT predicts severity of severe dengue effectively.

\section{REFERENCES:}

1. Westaway EG, Brinton MA, Gaidamovich S, Horzinek MC, Igarashi A, Kaariainen L et al: Flaviviridae. Intervirology. 1985; 24: 183-92.

2. Wang E, Ni H, Xu R, Barrett AD, Watowich SJ, Gubler DJ et al. Evolutionary relationships of endemic/epidemic and sylvatic dengue viruses. J Virol. 2000; 74: 3227-34.

3. Guzman MG, Kouri G. Dengue: an update. Lancet Infect Dis. 2002; 2: 33-42.

4. WHO. Revision of the International Health Regulations. World Health Assembly Resolution WHA 58.3, adopted by the 58th World Health Assembly, 2005. Available from http://www.who.int/gb/ebwha/pdf_files/WHA58/WHA58_3en.pdf

5. WHO. Geneva: WHO; 1997. Dengue haemorrhagic fever. Diagnosis, treatment, prevention and control pp.12-23.Available from whqlibdoc.who.int/ publications/1997/ 9241545003_eng.pdf.

6. WHO. Geneva: World Health Organization; 2009. Dengue: guidelines for diagnosis, treatment, prevention and control - New Ed. Available from www.who.int/tdr/publications/documents/dengue-diagnosis.pdf.

7. WHO TDR Global Alert and Response Dengue/Dengue Haemorrhagic Fever [webpage on Internet] Geneva: World Health Organization (WHO); 2013. [cited March 3,2013]. Available from:http://www.who.int/csr/disease/dengue/en/index.html.

8. Kulkarni MJ, Sarathi V, Bhalla V, Shivpuri D, Acharya U. Clinico-epidemiological profile of children hospitalized with dengue. Indian J Pediatr. 2010; 77: 1103-7. doi: 10.1007/s12098010-0202-2. Epub 2010 Oct. 2. 


\section{ORIGINAL ARTICLE}

9. Rasul CH, Hasan HAMN, A. Rasid AKMM., Khan MRH. Epidemiological factors of dengue hemorrhagic fever in Bangladesh. Indian Paediatr. 2002; 39: 369-371.

10. Shah GS, Islam S, Das BK. Clinical and laboratory profile of dengue infection in children. Kathmandu Univ Med J. 2006; 4: 40-43.

11. Mittal H, Faridi MM, Arora SK, Patil R. Clinicohematological profile and platelet trends in children with dengue during 2010 epidemic in north India. Indian J Pediatr. 2012; 79: 467-471. doi: 10.1007/s12098-011-0586-7. Epub 2011 Oct 29.

12. Shah I, Deshpande GC, Tardeja PN. Outbreak of dengue in Mumbai and predictive markers for dengue shock syndrome. J Trop Pediatr. 2004; 50: 301-305.

13. Kabra SK, Jain Y, Pandey RM, Madhulika, Singhal T, Tripathi P et al. Dengue haemorrhagic fever in children in the 1996 Delhi epidemic. Trans R Soc Trop Med Hyg 1999; 93: 294-298.

14. Joshi R, Baid V. Profile of dengue patients admitted to a tertiary care hospital in Mumbai. Turk J of Pediatr. 2011; 53: 626-631.

15. Ratageri VH, Shepur TA, Wari PK, Chavan SC, Mujahid IB, Yergolkar PN. Clinical profile and outcome of dengue fever cases. Indian J Pediatr 2005; 72: 705-706.

16. Narayanan M, Aravind MA, Thilothammal N, Prema R, Sargunam CS, Ramamurthy N et al. Dengue fever epidemic in Chennai-a study of clinical profile and outcome. Indian Pediatr. 2002; 39: 1027-1033.

17. Cao, Ngo XT, Wills TN, Kneen B, Nguyen R, Ta TT et al. Evaluation of the World Health Organization standard tourniquet test and a modified tourniquet test in the diagnosis of dengue infection in Vietnam. Trop Med Int Health. 2002; 7: 125-132.

18. Balmaseda A, Hammond SN, Pérez L, Tellez Y, Saborío SI, Mercado JC et al. Serotype-specific differences in clinical manifestations of dengue. Am J Trop Med Hyg. 2006; 74: 449-56.

19. Bharaj P, Chahar HS, Pandey A, Diddi K, Dar L, Guleria R et al Concurrent infections by all four dengue virus serotypes during an outbreak of dengue in 2006 in Delhi, India. Virol J.2008; 5:1.doi 10.1186/1743-422X-5-1.

20. Chaturvedi U, Nagar R, Shrivastava R. Dengue and dengue haemorrhagic fever: implications of host genetics. FEMS Immunol Med Microbiol 2006; 47: 155-66.

21. Long HT, Hibberd ML, Hien TT, Dung NM, Van Ngoc T, Farrar J et al. Patterns of gene transcript abundance in the blood of children with severe or uncomplicated dengue highlight differences in disease evolution and host response to dengue virus infection. J Infect Dis. 2009; 199: 537-46. doi: 10.1086/596507.

22. Dhooria GS, Bhat D, Bains HS. Clinical profile and outcome in children of dengue haemorrhagic fever in North India. Iran J Pediatr. 2008; 18: 222-228.

23. Gomber S, Ramachandran VG., Kumar S, Agarwal KN, Gupta P, Gupta P et al. Hematological observations as diagnostic markers in dengue hemorrhagic fever-a reappraisal. Indian Pediatr. 2001; 38: 477-481.

24. Setiawan MW, Samsi TK, Wulur H, Sugianto D, Pool TN. Dengue hemorrhagic fever: Ultrasound as an aid to predict the severity of the disease. Pediatr Radiol 1998; 28: 1-4.

25. Bessof K, Delorey M, Sun W, Hunsperger E. Comparison of Two Commercially Available Dengue Virus (DENV) NS1 Capture Enzyme-Linked Immunosorbent Assays Using a Single Clinical Sample for Diagnosis of Acute DENV Infection. Clin Vaccine Immunol. 2008; 15: 1513-8. 


\section{ORIGINAL ARTICLE}

26. Alcon S, Talarmin A, Debruyne M, Falconar A, Duebel V, Flamand M. Enzyme-Linked Immunosorbent Assay Specific to Dengue Virus Type 1 Nonstructural Protein NS1 Reveals Circulation of the Antigen in the Blood during the Acute Phase of Disease in Patients Experiencing Primary or Secondary Infections. J Clin Microbiol 2002; 40: 376-81.

27. Libraty DH, Young PR, Pickering D, Endy TP, Kalayanarooj S, Green S, et al. High circulating levels of the dengue virus nonstructural protein NS1 early in dengue illness correlate with development of dengue haemorrhagic fever. J Infect Dis. 2002; 186: 1165-8.

28. Dussart P, Labeau B, Lagathu G, Louis P, Nunes MRT, Rodrigues SG et al. Evaluation of an Enzyme Immunoassay for detection of dengue virus NS1 antigen I human serum. Clin Vaccine Immunol. 2006; 13: 1185-9.

29. Zulkarnain I. Gallbladder edema in dengue hemorrhagic fever and its association with Hematocrit levels and type of infections. Acta Med Indones 2004; 36: 84-6.

30. Gupta S, Singh SK, Taneja V, Goulatia RK, Bhagat A, Puliyel JM. Gall bladder wall edema in serology proven pediatric dengue hemorrhagic fever: a useful diagnostic finding which may help in prognostication. J Trop Pediatr. 2000; 46: 179-81.

31. Agarwal R, Kapoor S, Nagar R, Mishra A, Tandon R, Mathur A et al. A clinical study of the patients with dengue hemorrhagic fever during the epidemic of 1996 at Lucknow, India. Southeast Asian J Trop Med Public Health 1999; 30: 735-40.

32. Richards AL, Bagus R, Baso SM, Follows GA, Tan R, Graham RR, et al. The first reported outbreak of dengue hemorrhagic fever in Irian Jaya, Indonesia. Amer J Trop Med Hyg. 1997; 57: 49-55.

33. Batra P, Saha A, Chaturvedi P, Vilhekar KY, Mendiratta DK. Outbreak of dengue infection in rural Maharashtra. Indian J Pediatr. 2007; 74: 794-795.

34. Mandal SK, Ganguly J, Sil K, Chatterjee S, Chatterjee K, Sarkar P et al. Clinical profiles of dengue fever in a teaching hospital of eastern India. Natl J Med Res. 2013; 3: 173-176.

\begin{tabular}{|c|c|c|c|c|c|c|c|}
\hline \multirow{3}{*}{$\begin{array}{l}\text { Age Grp } \\
\text { (in years) }\end{array}$} & \multirow{3}{*}{$\mathbf{n}$} & \multicolumn{6}{|c|}{ Dengue Classification } \\
\hline & & \multicolumn{2}{|c|}{$\begin{array}{l}\text { Without Warning } \\
\text { Signs }(n=52)\end{array}$} & \multicolumn{2}{|c|}{$\begin{array}{c}\text { With Warning } \\
\text { Signs }(n=40)\end{array}$} & \multicolumn{2}{|c|}{$\begin{array}{c}\text { Severe } \\
(n=8)\end{array}$} \\
\hline & & No. & $\%$ & No. & $\%$ & No. & $\%$ \\
\hline$<1$ & 2 & 2 & 3.85 & 0 & 0.00 & 0 & 0.00 \\
\hline $1-4$ & 3 & 3 & 5.77 & 0 & 0.00 & 0 & 0.00 \\
\hline$>4-8$ & 21 & 11 & 21.15 & 10 & 25.00 & 0 & 0.00 \\
\hline$>8-12$ & 23 & 8 & 15.38 & 12 & 30.00 & 3 & 37.50 \\
\hline$>12$ & 51 & 28 & 53.85 & 18 & 45.00 & 5 & 62.50 \\
\hline Total & 100 & 52 & 100.00 & 40 & 100.00 & 8 & 100.00 \\
\hline
\end{tabular}




\section{ORIGINAL ARTICLE}

\begin{tabular}{|c|c|c|c|c|c|c|c|c|}
\hline \multirow{3}{*}{ Symptoms/Signs } & \multirow{3}{*}{$\mathbf{N}$} & \multicolumn{6}{|c|}{ Dengue Classification } & \multirow{3}{*}{ 'p' Value } \\
\hline & & \multicolumn{2}{|c|}{\begin{tabular}{|c|} 
Without warning \\
signs $(n=52)$
\end{tabular}} & \multicolumn{2}{|c|}{$\begin{array}{l}\text { With warning } \\
\text { signs }(n=40)\end{array}$} & \multicolumn{2}{|c|}{$\begin{array}{c}\text { Severe } \\
(n=8)\end{array}$} & \\
\hline & & No. & $\%$ & No. & $\%$ & No. & $\%$ & \\
\hline Fever & 100 & 52 & 100.00 & 40 & 100.00 & 8 & 100.00 & NA \\
\hline Vomiting & 42 & 0 & 0.00 & 34 & 85.00 & 8 & 100.00 & $<0.001$ \\
\hline Pain Abdomen & 42 & 1 & 1.92 & 33 & 82.50 & 8 & 100.00 & $<0.001$ \\
\hline Myalgia & 69 & 31 & 59.62 & 30 & 75.00 & 8 & 100.00 & 0.041 \\
\hline Rash & 13 & 0 & 0.00 & 5 & 12.50 & 8 & 100.00 & $<0.001$ \\
\hline Bleeding Manifest'n & 7 & 0 & 0 & 1 & 2.50 & 6 & 75.00 & $<0.001$ \\
\hline Positive Hess Test & 8 & 0 & 0.00 & 0 & 0.00 & 8 & 100.00 & $<0.001$ \\
\hline Respiratory Distress & 5 & 0 & 0.00 & 0 & 0.00 & 5 & 62.50 & $<0.001$ \\
\hline Altered Sensorium & 4 & 0 & 0.00 & 0 & 0.00 & 4 & 50.00 & $<0.001$ \\
\hline Pallor & 21 & 7 & 13.46 & 6 & 15.00 & 8 & 100.00 & $<0.001$ \\
\hline Lymphadenopathy & 7 & 2 & 3.85 & 1 & 2.50 & 4 & 50.00 & $<0.001$ \\
\hline Flushing & 7 & 2 & 3.85 & 1 & 2.50 & 4 & 50.00 & $<0.001$ \\
\hline Cold Extremities & 7 & 1 & 1.92 & 0 & 0.00 & 6 & 75.00 & $<0.001$ \\
\hline Hepatomegaly & 39 & 20 & 38.46 & 11 & 52.50 & 8 & 100 & 0.004 \\
\hline
\end{tabular}

\begin{tabular}{|c|c|}
\hline Investigation & Mean(Range) \\
\hline Hemoglobin & $10.75(6.30-14.20) \mathrm{g} / \mathrm{dl}$ \\
\hline Hematocrit & $33.91 \%(17.40-43.70)$ \\
\hline Total leukocyte count & $4.9 \times 10^{9}\left(1.7 \times 10^{9}-17 \times 10^{9}\right) / \mathrm{L}$ \\
\hline Platelet count & $82 \times 10^{9}\left(15 \times 10^{9}-274 \times 10^{9}\right) / \mathrm{L}$ \\
\hline Prothrombin time & $13.93(11-30) \mathrm{sec}^{*}$ \\
\hline Activated partial thromboplastin time & $31.50(26-46) \mathrm{sec}^{*}$ \\
\hline SGOT & $165.26(26-900) \mathrm{U} / \mathrm{L}$ \\
\hline SGPT & $124.22(24-765) \mathrm{U} / \mathrm{L}$ \\
\hline Serum albumin & $3.90(2.20-4.60) \mathrm{g} / \mathrm{dl}$ \\
\hline \multicolumn{2}{|c|}{$*$ Sec-seconds } \\
\hline Table 3: Laboratory investigations in study subjects
\end{tabular}

\begin{tabular}{|c|c|c|c|c|c|c|c|c|}
\hline \multirow{2}{*}{$\begin{array}{c}\text { Test } \\
\text { Result }\end{array}$} & N & \multicolumn{6}{|c|}{$\begin{array}{c}\text { Without warning } \\
\text { signs }\end{array}$} & \multicolumn{2}{|c|}{$\begin{array}{c}\text { With warning } \\
\text { signs (n=40) }\end{array}$} & \multicolumn{2}{|c|}{$\begin{array}{c}\text { Severe } \\
\text { (n=8) }\end{array}$} & \multirow{2}{*}{ 'p' Value } \\
\cline { 2 - 8 } & & No. & $\mathbf{\%}$ & No. & $\mathbf{\%}$ & No. & \% & \\
\hline NS1 Positive & 68 & 41 & 78.85 & 27 & 67.50 & 0 & 0.00 & $<0.001$ \\
\hline IgM Positive & 35 & 12 & 23.08 & 18 & 45.00 & 5 & 62.50 & 0.012 \\
\hline IgG Positive & 26 & 8 & 15.38 & 10 & 25.00 & 8 & 100.00 & $<0.001$ \\
\hline
\end{tabular}

Table 4: Serological analysis of the study subjects 


\section{ORIGINAL ARTICLE}

\begin{tabular}{|c|c|c|c|c|c|}
\hline \multirow[b]{2}{*}{ Chest X-ray } & \multirow[b]{2}{*}{$\begin{array}{l}\text { No. of } \\
\text { cases }\end{array}$} & \multirow[b]{2}{*}{ \%age } & \multicolumn{3}{|c|}{ Dengue Classification } \\
\hline & & & $\begin{array}{l}\text { Without Warning } \\
\text { Signs }(n=52)\end{array}$ & $\begin{array}{c}\text { With } \\
\text { Warning } \\
\text { Signs }(n=40)\end{array}$ & $\begin{array}{c}\text { Severe } \\
(n=8)\end{array}$ \\
\hline Normal & 80 & 80 & 49 & 29 & 2 \\
\hline Pleural effusion left side & 1 & 1 & 0 & 0 & 1 \\
\hline Pleural effusion right side & 15 & 15 & 3 & 10 & 2 \\
\hline Pleural effusion bilateral & 4 & 4 & 0 & 1 & 3 \\
\hline Total & 100 & 100 & 52 & 40 & 8 \\
\hline
\end{tabular}

Table 5: Chest X-Ray findings in study subjects

\begin{tabular}{|c|c|c|c|c|c|c|}
\hline \multirow[b]{2}{*}{ USG } & \multirow[b]{2}{*}{$\begin{array}{l}\text { No. of } \\
\text { cases }\end{array}$} & \multirow[b]{2}{*}{$\begin{array}{c}\text { Percentage } \\
(\%)\end{array}$} & \multicolumn{3}{|c|}{ Dengue Classification } & \multirow[b]{2}{*}{$P$ value } \\
\hline & & & $\begin{array}{l}\text { Without Warning } \\
\text { Signs }(n=52)\end{array}$ & $\begin{array}{l}\text { With Warning } \\
\text { Signs }(n=40)\end{array}$ & $\begin{array}{c}\text { Severe } \\
(n=8)\end{array}$ & \\
\hline Ascites & 4 & 4 & 2 & 2 & 0 & \multirow{8}{*}{$<0.001$} \\
\hline Pleural Effusion(PE) & 9 & 9 & 0 & 2 & 7 & \\
\hline Ascites + PE & 8 & 8 & 1 & 6 & 1 & \\
\hline Ascites + PE+GBWT & 3 & 3 & 0 & 0 & 3 & \\
\hline Hepatosplenomegaly(HS) & 7 & 7 & 0 & 7 & 0 & \\
\hline Ascites + HS & 1 & 1 & 0 & 0 & 1 & \\
\hline Hepatomegaly $(\mathrm{H})$ & 4 & 4 & 2 & 2 & 0 & \\
\hline $\mathrm{H}+\mathrm{PE}$ & 1 & 1 & 0 & 1 & 0 & \\
\hline
\end{tabular}

Table 6: Findings of ultrasonography (USG) scan in study subjects

* Altered sensorium.

\begin{tabular}{|c|c|c|c|c|c|c|c|c|c|c|}
\hline $\begin{array}{l}\text { Clinical features } \\
\text { (in \%age) }\end{array}$ & $\begin{array}{c}\text { Agarwal } \\
\text { et } \text { al }^{31}\end{array}$ & $\begin{array}{c}\text { Joshi } \\
\text { et } \text { al }^{15}\end{array}$ & $\begin{array}{c}\text { Richard } \\
\text { et } \mathbf{a l}^{32}\end{array}$ & $\begin{array}{c}\text { Ratageri } \\
\text { et al }{ }^{17}\end{array}$ & $\begin{array}{l}\text { Mittal } \\
\text { et al }{ }^{11}\end{array}$ & $\begin{array}{l}\text { Batra } \\
\text { et } \mathbf{~ a l}^{33}\end{array}$ & $\begin{array}{c}\text { Mandal } \\
\text { et } \text { al }^{34}\end{array}$ & $\begin{array}{c}\text { Shah } \\
\text { et al }{ }^{12}\end{array}$ & $\begin{array}{c}\text { Narayanan } \\
\text { et }^{20}{ }^{20}\end{array}$ & $\begin{array}{c}\text { Present } \\
\text { Study }\end{array}$ \\
\hline Fever & 100 & 100 & 100 & 100 & 100 & 100 & 100 & 100 & 98.3 & 100 \\
\hline Headache & - & 15.8 & 96.70 & 22 & 63 & - & 62.16 & - & 28.8 & - \\
\hline Rash & & - & 26 & 24 & - & 24 & 37.84 & 41 & 8.5 & 13 \\
\hline Myalgia & - & 7 & 39.1 & - & - & 8 & - & - & - & 69 \\
\hline Pain Abdomen & 49 & 31.5 & 39.1 & 52 & 71 & 52 & - & - & 23.7 & 42 \\
\hline Vomiting & 68 & 40.3 & 47.8 & 72 & - & 72 & - & 86.60 & 83 & 42 \\
\hline $\begin{array}{l}\text { Alt.sens* } \\
\text { /seizures }\end{array}$ & 8 & 12.3 & 17.4 & 20 & - & - & 11.11 & 48.70 & - & 4 \\
\hline Petechiae & - & - & 43.5 & - & - & - & - & - & - & 3 \\
\hline Hemetemesis & - & 31.8 & - & 18 & 35.5 & - & - & - & 66.1 & 1 \\
\hline Melena & - & 27.2 & - & - & - & - & - & - & - & 1 \\
\hline Epistaxis & - & 63.6 & - & - & - & - & - & - & - & 2 \\
\hline $\begin{array}{c}\text { Lymphadenop } \\
\text { a-thy }\end{array}$ & - & 18.2 & - & 4 & - & - & - & - & 10.2 & 7 \\
\hline Shock & 8.2 & 31.6 & 11.1 & 8 & 42 & - & - & 35.3 & 22 & 7 \\
\hline Hepatomegaly & 72 & 66.6 & - & - & 31.1 & 56 & - & - & 52.5 & 39 \\
\hline
\end{tabular}




\section{ORIGINAL ARTICLE}

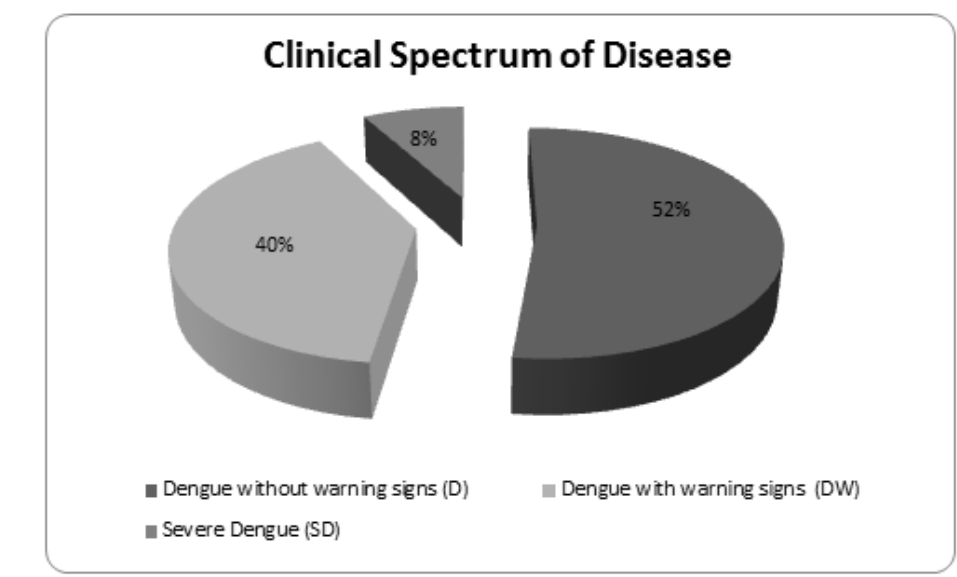

Fig. 1: Categorization of study subjects according to the new WHO / TDR Classification 2009

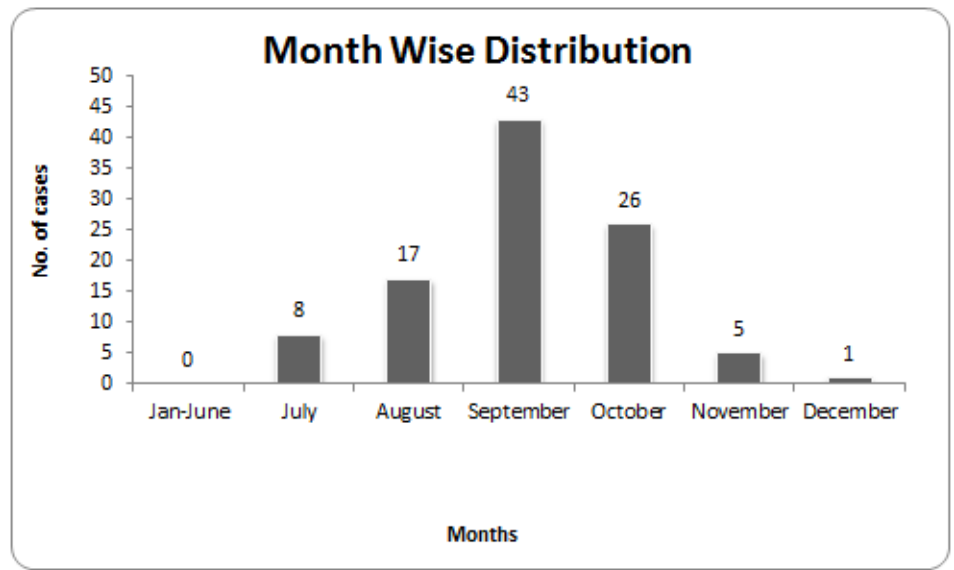

\section{Fig 2: Month-wise distribution of study subjects}

\section{AUTHORS:}

1. Manisha Rathi

2. Rupesh Masand

3. Alok Purohit

\section{PARTICULARS OF CONTRIBUTORS:}

1. Post Graduate, Department of Paediatrics, NIMS Medical College, Jaipur, Rajasthan.

2. Professor, Department of Paediatrics, NIMS Medical College, Jaipur, Rajasthan.

3. Professor, Department of Paediatrics, NIMS Medical College, Jaipur, Rajasthan.

\section{FINANCIAL OR OTHER} COMPETING INTERESTS: None

\section{NAME ADDRESS EMAIL ID OF THE} CORRESPONDING AUTHOR:

Rupesh Masand,

Sector-4/467,

Malviya Nagar,

Jaipur-302017, Rajasthan.

E-mail: masand.rupesh72@gmail.com

Date of Submission: 15/04/2015.

Date of Peer Review: 16/04/2015.

Date of Acceptance: 06/05/2015.

Date of Publishing: 13/05/2015. 